\title{
Effects of ibuprofen and venlafaxine on behavioural parameters in freshwater bivalve Unio tumidus
}

\author{
Joanna Chmist-Sikorska ${ }^{1, *}$, Krzysztof Szoszkiewicz ${ }^{2}$, Arkadiusz Wencka ${ }^{2}$, Martyna Szczepaniak $^{2}$, Joanna Szymczak $^{2}$ \\ and Maciej Kujawski ${ }^{2}$. \\ ${ }^{1}$ Institute of Meteorology and Water Management - National Research Institute, Warszawa, Poland \\ ${ }^{2}$ Poznan University of Life Sciences, Poznan, Poland
}

\begin{abstract}
The pollution of aquatic ecosystems by pharmaceuticals is presently recognized as a serious threat. The drug residues may contaminate surface waters via sewage discharges as well as improper disposal of industrial waste. Very few studies focused on the effects of drug pollutants on behaviour of invertebrates. In this study the effects of ibuprofen and venlafaxine on activity of the Unio tumidus were studied. Changes in behaviours were analysed at concentrations corresponding to wastewater discharges $\left(3.4,6.8\right.$ and $\left.13.6 \mu \mathrm{gL}^{-1}\right)$. At dosage of $3.4 \mathrm{\mu gL}^{-1}$, ibuprofen affected the activity time and shell opening level. The reduction in activity was particularly evident during the first few days. The same dose of venlafaxine caused hyperactivity of bivalves during the first few days of exposition. The highest doses $\left(13.6 \mathrm{\mu gL}^{-1}\right)$ same drugs promoted reduction of activity and shell opening level. Moreover, exposure to these drugs resulted in the reduced water filtering time and hence its purification. The Unio tumidus reaction may indicate negative reaction of other aquatic species to the tested drugs.
\end{abstract}

\section{Introduction}

Water pollution is considered as an extensive term comprising of many agents derived from multiple sources. Including both pathogens (viruses, coliform bacteria, protozoan parasites) and chemical compounds like toxic metals, fertilizers, pesticides, arsenic, perchlorate, polycyclic aromatic hydrocarbons and polychlorinated biphenyls $[1,2,3]$. However, at a time where pharmaceuticals are used commonly on global scale, it makes pollution problem even bigger.

Currently, there are several thousand substances belonging to the group of pharmaceuticals on the global scale. One of the most often used pharmaceuticals are nonsteroidal anti-inflammatory drugs, such as ibuprofen. The NSAIDs can be found in surface and groundwater in different concentrations because of the global consumption and limited efficiency of sewage treatment processes. Klimaszyk and Rzymski [4] found sources of NSAIDs in the environment, which are e.g.: hospital sewage, domestic and treated wastewater, effluents from pharmaceutical manufactures, etc. The technologies used-the most common biological sewage treatment plants do not allow you to complete the distribution of drugs $[5,6]$. Semi-purified water goes then to the environment. Poland is in the third place in Europe (behind Greece and France) in the quantity of used pharmaceuticals in the year 2016 [7]. The popularity of non-steroidal anti-inflammatory drugs is primarily due to widespread access to them [8].
The other group of pharmaceuticals which become significant threat for aquatic ecosystems are psychotropic drugs. Based on Thomas et al. [9] the average annual growth rates for usage of psychotropics, especially in group of adolescents increased rapid after 1999. Another authors clearly indicate that the consumption of pharmaceuticals, in different age groups increases year by year $[4,10,11,12]$. Thus, the amount of wastewater contaminated with psychoactive substances increased.

Currently, just few information is available on the concentration of ibuprofen detected in water in Poland. Kasprzyk-Hordern et al. [13] found that in 2008 about 79 $\mathrm{ng} / \mathrm{l}$ of ibuprofen was found in Warta river. However, there is lack of information about concentration of psychoactive pharmaceuticals in surface water and their negative impact to aquatic animals as well as human health. Despite the fact that the efficiency of removing drugs from raw sewage is very high $(97 \pm 100 \%)$ according to the authors, their presence is still detectable $[14,15]$. In addition, Kot-Wasik et al. found that in 2016 in tap water in Gdańsk concentration of this ibuprofen exceed 223,6 $\mathrm{ngL}^{-1}$ [16].

The various studies showed that anti-inflammatory drugs significantly affect aquatic organisms. In experimental conditions the half-life of ibuprofen can vary between 19 to 493 days, while venlafaxine between 5.7 to 28.5 days $[17,18,19]$. During this time, aquatic ecosystems are exposed to the negative effects of drugs. Most known and well documented example of

\footnotetext{
*Corresponding author: joanna.chmist@op.pl
} 
pharmaceuticals impact on living organisms was the feminization of male fish $[20,21,22]$. In addition, the rainbow trout under a stress conditions caused by drugs, showed changes in the gills and damage kidneys [23]. NSAIDs affect toxic to phytoplankton, zooplankton and cyanobacteria [23] and inhibit the growth of Lemna spp.. However, in the case of Daphnia magna especially ibuprofen may inhibit reproductive capacity and inhibit the growth [24]. Undoubtedly increasing occurrence of pharmaceuticals contributes to serious changes in water ecosystems[17].

Although the impact of pollution caused by many of the pharmaceuticals still there are large data gaps, a few of them were identified as dangerous for the aquatic environment. There is plenty of data about negative effect of drugs to fish population and just a little about invertebrates. Therefore, the aim of this study was to check the toxic effect of ibuprofen as well as venlafaxine to Polish native bivalve species (Unio tumidus). The effect of the cumulative dose of pharmaceuticals on the behavior of bivalves was tested and the authors did not analyze the lethal concentrations was not considered.

\section{Materials and methods}

\subsection{Collection of 6-year old ( \pm 2 ) bivalves, pre- treatment and exposure}

The 6-year old Unio tumidus were retrieved in 2018 from small lake located $16 \mathrm{~km}$ southwest of Poznan, Poland with no inputs of effluent water. The bivalves were placed in the laboratory aquarium $(80 \mathrm{~L})$ containing bottled water. They were fed dry phytoplankton twice a week. Bivalves were kept under controlled light and dark conditions ( $12 \mathrm{~h}: 12 \mathrm{~h}$ ). Typical water quality parameters of the bottled water are: $\mathrm{pH} 8.0$, calcium cation $\mathrm{Ca}^{2+}$ $72,14 \mathrm{mgL}^{-1}$, sodium cation $\mathrm{Na}^{+} 57,14 \mathrm{mgL}^{-1}$, magnesium cation $\mathrm{Mg}^{+} 34,03 \mathrm{mgL}^{-1}$, bicarbonate anion $\mathrm{HCO}_{3}^{-} 514 \mathrm{mgL}^{-1}$, sulfate anion $\mathrm{SO}^{2-}{ }_{4} 15,02 \mathrm{mgL}^{-1}$, chloride anion $\mathrm{Cl}^{-} 13,10 \mathrm{mgL}^{-1}$ and temperature $12^{\circ} \mathrm{C}$. Bivalves $(\mathrm{n}=16)$ were then placed in oxygenated (using airstones) aquarium $(25 \mathrm{~cm}$ high $\times 25 \mathrm{~cm}$ wide $\times 150 \mathrm{~cm}$ long) filled with bottled water to a depth of $20 \mathrm{~cm}$. In each scenario of experiment, eight replicates were made.

In scenario one, bivalves spent one week in a normal condition (control period), then they were exposed for a one week to nominal concentration of $4 \mu \mathrm{gL}^{-1}$ ibuprofen, which was increased week by week up to $12 \mu \mathrm{gL}^{-1}$ (analytical grade ibuprofen from HASCO-LEK). In scenario two, as in the previous study, bivalves spent one week in a normal condition (control period), then they were exposed for a one week to nominal concentration of $4 \mu \mathrm{gL}^{-1}$ venlafaxine, which was increased week by week up to $12 \mu \mathrm{gL}^{-1}$ (analytical grade venlafaxine from PFIZER). There were no significant differences in weight or dimensions of the chosen bivalves. During the treatment, the bivalves were not fed.

\subsection{Data measurement and data collection}

Hall sensor technologies were used in this experiment. The methods similar to developed by Wilson et al. (2005) [25] and modified by Robson et al. (2007) [26] were used. However, Robson et al. (2009) [27] thought that both, Wilson et al. (2005) as well as Robson et al. (2007) did not calibrated all possible gape angles. Therefore in our experiment we used comercial software Symbio (Prote Technologie dla Środowiska company) to avoid calibration dilemma. Moreover, bivalves were placed on the special construction shown in Figure 1. Ferrite magnet were glued to the left shell of each bivalve using a cyanoacrylate adhesive. Behavioral traits (activity time, shell opening level) were measured continuously. The magnetic field strength measurements were first converted to the distance between the magnet and the probe in millimeters, then converted to the percentage of the opening level of the shells, according to the formulas:

$$
\begin{aligned}
& D=-0.871 \ln (x)+7.44 \\
& P=-43.4 \ln (D)+345.74
\end{aligned}
$$

D- distance between the magnet and the probe ( $\mathrm{mm})$,

$\mathrm{x}$ - magnetic field intensity $(\mathrm{mV})$,

P- percentage of the opening level (\%).

Calculations were made automatically by the controller. Aproximately 86400 data per day were collected for each bivalve.

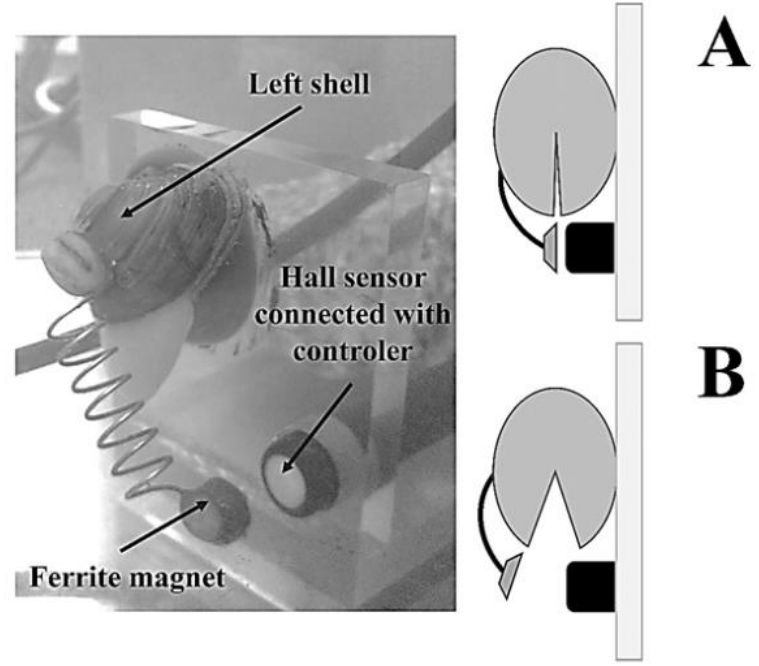

Fig. 1. Set-up of the bivalves valve movement monitor. A- the valves closed, the maximal magnetic field at the sensor. B- the valves opened, the minimal magnetic field at the sensor

\subsection{Behavior data analysis}

Each experiment was divided into four phases: control period, treated with $4 \mu \mathrm{gL}^{-1}$, treated with $\mu \mathrm{gL}^{-1}$ and treated with $12 \mu \mathrm{gL}^{-1}$ of ibuprofen and venlafaxine. Bivalves behaviour was analyzed for significant differences between the control and all treated period. Two behavioral traits were tested: activity time and shell opening level. The activity time was measured as a time when bivalve's shells were open and considered to be 
filtering over a period of time. Shell opening level was a daily value of mean percentage level of shell opening. It included both active and inactive periods. Experiment was carried out for 28 days for each drug, during which each period lasted 7 days. Data from 28 days were extracted for statistical analysis of significant effects for activity time and shell opening level. The periods were selected before and during each ibuprofen and venlafaxine exposure scenario. Each period was analyzed for normal distribution using Shapiro-Wilks test and the parametric analysis of variance ANOVA were used. The STATISTICA 13.1 software package was used in analysis.

\section{Results}

Activity time of the bivalves exposed to ibuprofen was affected by concentration. However, the significant differences were observed only between control and all treated periods $(\mathrm{F}=9.94, \mathrm{p}=0.0002)$. There were no differences between individual pharmaceuticals concentrations $(\mathrm{F}=2.36, \mathrm{p}=0.122)$. During the control period mean daily activity time exceed 20 hours per day. After exposure to $4 \mu \mathrm{gL}^{-1}$ of ibuprofen it decreased to 15 hours per day. The lowest mean daily activity time (10 hours per day) was observed during exposition to 12 $\mu \mathrm{gL}^{-1}$ of ibuprofen (Fig. 2A).

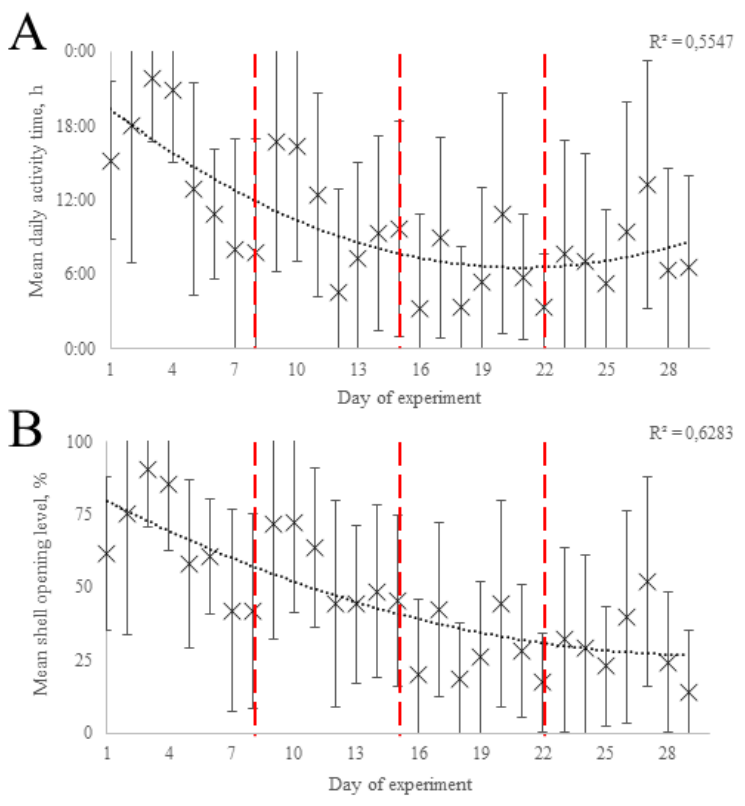

Fig. 2. Activity time (A) and shell opening level (B) measured in the laboratory for the control and ibuprofen treatment (4 $\mu \mathrm{gL}^{-1}, 8 \mu \mathrm{gL}^{-1}, 12 \mu \mathrm{gL}^{-1}$ ) periods

Shell opening level exposed to ibuprofen was affected by concentration as well. Control period was significantly different from treatment periods $(\mathrm{F}=12.47$, $\mathrm{p}<0.0001)$. Between treated periods significant differences were not observed $(\mathrm{F}=1.61, \mathrm{p}=0,228)$. During control periods mean daily shell opening level exceed $80 \%$. After exposure to ibuprofen this behavioral trait showed downward trend. Exposure to $4 \mu \mathrm{gL}^{-1}$ of ibuprofen caused a drop in the shell opening level by
$20 \%$ in comparison to the control. The lowest mean daily shell opening level (48\%) was observed during exposition to $12 \mu \mathrm{gL}^{-1}$ of ibuprofen (Figure $2 \mathrm{~B}$ ).

Activity time of the bivalves exposed to venlafaxine, as in the previous scenario, was affected by concentration. The significant differences were observed between control, 8 and $12 \mu \mathrm{gL}^{-1} \quad(\mathrm{~F}=6.82, \mathrm{p}=0.0016)$. There were no differences between individual pharmaceuticals concentrations as well as between control and $4 \mu \mathrm{gL}^{-1}$. During the control period mean daily activity time ranged from 13 to 22 hours $(15 \pm 7 \mathrm{~h})$. After exposure to $4 \mu \mathrm{gL}^{-1}$ of venlafaxine it decreased to $10 \pm 8$ hours per day. The lowest mean daily activity time (less than 7 hours per day) was observed during exposition to $8 \mu \mathrm{gL}^{-1}$ and $12 \mu \mathrm{gL}^{-1}$ of venlafaxine (Figure 4A).

Data obtained during the continuous monitoring of mollusc behaviour are shown in Fig. 3. During the control period, five periods were separated during which the shell level was less than $50 \%$. This value is considered as the boundary between normal and stress behaviour. In the case of control period, these events (due to their short duration) were probably caused by external factors, such as light or noise. However, during treatment period with exposition to $4 \mu \mathrm{gL}^{-1}$ of ibuprofen, the events of the reduced shell opening level exceed 24 hours. This means that all bivalves showed a stress reaction. Similarly, in the case of further treatment periods, the shell opening for more than half of the analyzed time did not exceed $50 \%$. Especially at a concentration of $12 \mu \mathrm{gL}^{-1}$ (last 3 days) bivalves remained closed for the majority of the analyzed time without activity.

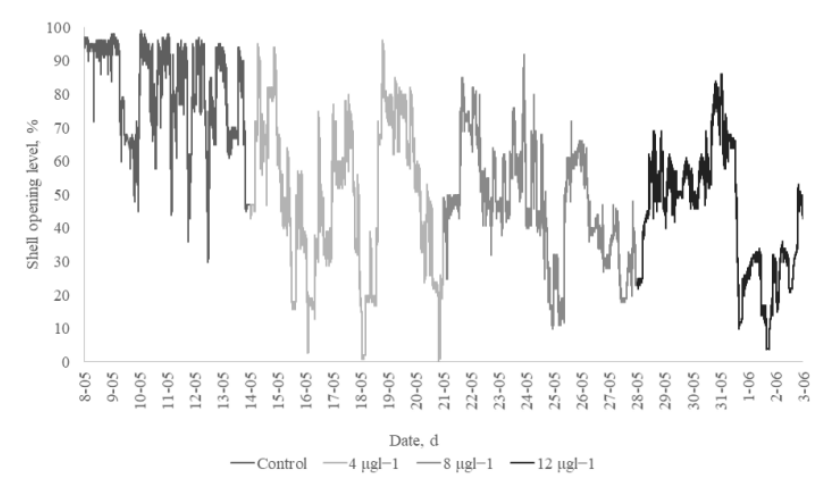

Fig. 3. Changes in shell opening level in a Unio tumidus over a 26 days period of ibuprofen treatment

Changes of bivalves behaviour were also observed in the case of shell opening level. Control period was significantly different from exposure to $8 \mu \mathrm{gL}^{-1}$ and 12 $\mu \mathrm{gL}^{-1}(\mathrm{~F}=13,32, \mathrm{p}<0.0001)$. However, there was no significant different between control and exposure to 4 $\mu \mathrm{gL}^{-1}$. During control period mean daily shell opening level ranged from $60 \%$ to $90 \%$. After exposure to venlafaxine the behavioral trait showed downward trend. However, exposure to $4 \mu \mathrm{gL}^{-1}$ of venlafaxine did not significantly reduce the shell opening level. It was about $9 \%$ in comparison to the control. The lowest mean daily shell opening level (28\%) was observed during exposition to $12 \mu \mathrm{gL}^{-1}$ of venlafaxine (Figure $4 \mathrm{~B}$ ). 
Data obtained during the continuous monitoring of bivalves behaviour are shown in Figure 5. During the control period, three periods were separated during which the shell level was less than $50 \%$. However, there was also a period, during which the mean shell opening level decrease below $20 \%$. These event (due to their $<10$ hours duration) were caused by external factors. However, after the introduction of the venlafaxine, the activity of mussels has increased rapidly. The reduced of shell opening level occurred during third day of exposition, and over next four days did not increased. This means that all bivalves showed a stress reaction. Similarly, in the case of further treatment periods, the shell opening for more than half of the analyzed time did not exceed $60 \%$.

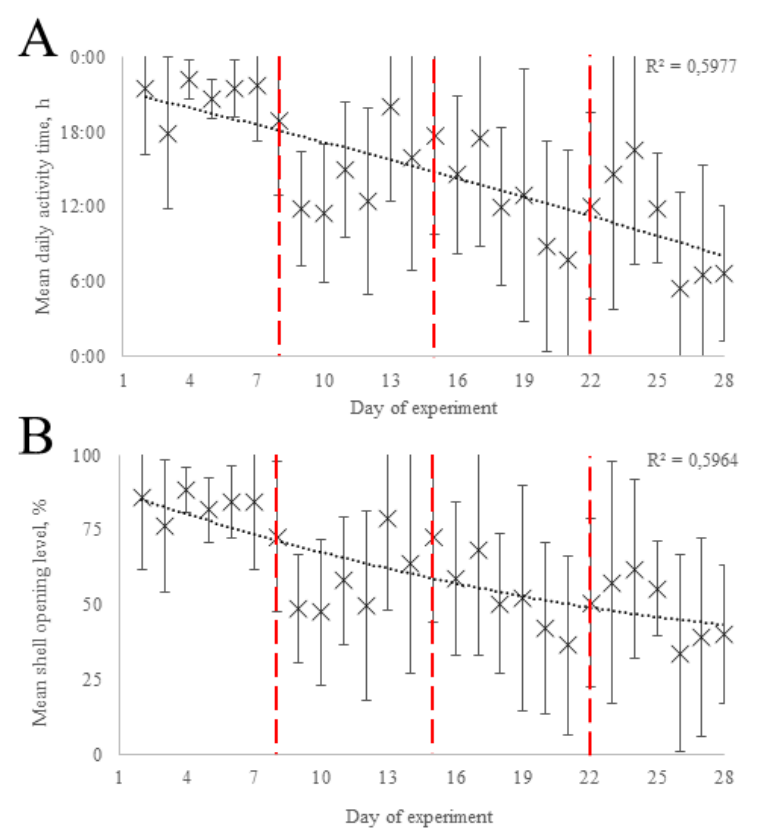

Fig. 4. Activity time (A) and shell opening level (B) measured in the laboratory for the control and venlafaxine treatment (4

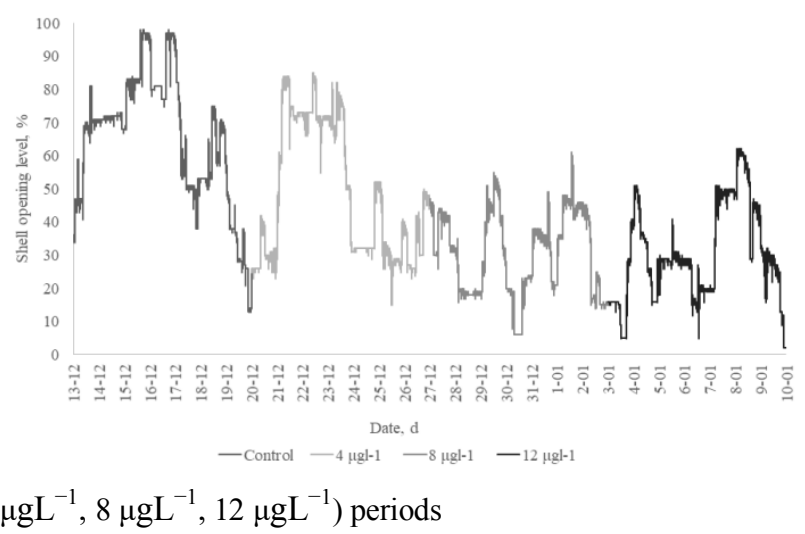

Fig. 5. Changes in shell opening level in a Unio tumidus over a 26 days period of venlafaxine treatment

\section{Discussion}

According to the current ecotoxicological works and European Medicines Agency guidelines, there are a various approaches for risk assessment tests associated with pharmaceuticals effect on aquatic organisms. However, they are mainly quantified based on acute toxity methods (LC50, LD50 etc.). Our research showed that ibuprofen as well as venlafaxine contamination may affect bivalves behavioural reactions, which cannot be identified by mortality tests. We found that both drugs caused reduction of activity time (Fig. 2A, 4A) and reduction of shell opening level (fFig.2B, 4B). However, even at $12 \mu \mathrm{gL}^{-1}$ concentration lethal states were not observed.

Our research showed that ibuprofen and venlafaxine contamination generates avoidance behaviour, interpreted as an activity decrease. In the case of ibuprofen, difference between control and treated period in activity time is more than 8 hours (at $12 \mu \mathrm{gL}^{-1}$ concentration). Similar result found Marchlewicz et al. [28]. They noticed changes in the activity time of Gammarus pulex treated with small doses of ibuprofen $\left(0.1-10 \mu \mathrm{gL}^{-1}\right)$. They observed a $35 \%$ drop in the activity time of this crustacean after using ibuprofen in the amount of $1 \mu \mathrm{gL}^{-1}$. In our studies on tumidus the reaction was significant in the ibuprofen concentration found in surface waters.

The negative effect of ibuprofen on bivalves behavioural reaction may be accelerated by the appearance of another drugs. Szymonik and Lach [29] indicated that the toxicity of NSAIDs increases in mixtures with other pharmaceutical substances. They showed that ibuprofen in a mixture with acetylsalicylic acid, naproxen and diclofenac has a much higher toxicity in relation to Daphnia magna than when it occurs alone. Due to that reason the unknown effects of multiple pharmaceutical exposure warrants further studies.

The concentrations of an ibuprofen as well as mix of different pharmaceutical products affect bivalves behavior. The rate of drugs concentrations increase in water is alarming [30]. It should also be emphasized that our research took place in laboratory conditions. Other behavioural reactions under real conditions cannot be excluded. Further, the use of pharmaceutical increases every year. Therefore, higher concentrations of pharmaceutical residues in aquatic systems can be expected to appear. Especially, because of a rapid increase of drugs availability for worldwide population [31]. The results we received from the study enhances ecologically significant effects of NSAIDs which affect aquatic ecosystems generally

The research we conducted confirms findings of Bueno et al. [32], claiming that venlafaxine is being accumulated in bivalves and possibly other aquatic animals. This pharmaceutical belongs to group of chemicals called serotonin and norepinephrine reuptake transporters (SSRIs), and we were able to detect reaction of the studied organisms, since serotonin is a major neuroremodulator in them. Due to serotonin playing vital role in physiological and behavioral functions of bivalve, such as gill ciliary (Fong and Ford, 2014) [33], we were able to directly observe its' effect. The $30-60 \%$ reduction in shell opening resulted from decreased nervous excitability caused by blocking reabsorbtion of neurotransmitters from synapsis cleft. We suspect this is 
also the same reason for shortening of bivalves daily activity time. Because Unio tumidus is a freshwater species we did not observe the significant results with the lowest concentration of the substance of $4 \mu \mathrm{gL}^{-1}$. As observed by Di Poi et al. [34] venlafaxine is more toxic to seawater bivalves than to freshwater ones. This issue is very problematic when considering a distribution of this pharmaceutical in environment over time. Minguez et al. [35] it have been found that venlafaxine is one of the most prevalent antidepressant, as being detected in Orne river $\left(\mathrm{C}=4.8 \mathrm{ngL}^{-1}\right)$ it was still present in the sea at the river's estuary, at concentration $1.3 \mathrm{ngL}^{-1}$ [34].

Considering the rapid behavioural change of mussels, we conclude that Unio tumidus is able to detect the presence of pharmaceuticals in water. The significant reduction in the activity and in the shell opening level at a concentration of $4 \mu \mathrm{gL}^{-1}$ indicates high sensitivity of molluscs to this group of drugs. Our previous studies $[36,37]$ showed, that Unio tumidus is sensitive to other pollutants, such as heavy metals, nitrogen compounds etc. However, during our experiment, bivalves were not fed, which may also affect the test result, but the 28-day period is not long enough to conclude about the possible side effects of a lack of food. Under real conditions, the rate at which the substance spreads are also affected by temperature, which was constant in the experiment. Therefore, this experiment should be treated as an introduction to subsequent studies, because considering the amount of new pharmaceuticals present in the water, as well as physical properties of water (as temperature or $\mathrm{pH}$ ), further studies on the sensitivity of Unio tumidus to such kind of pollutants seem necessary.

\section{Acknowledgements}

Publication is funded by the Polish National Agency for Academic Exchange under the International Academic Partnerships Programme from the project „Organization of the 9th International Scientific and Technical Conference entitled Environmental Engineering, Photogrammetry, Geoinformatics - Modern Technologies and Development Perspectives"

\section{References}

1. P. Stackelberg, E. Furlong, M. Meyer, S. Zaugg, A. Henderson, D. Reissman, Science of the Total Environ., 329(1-3), 99-113 (2004)

2. R. Schwarzenbach, T. Egli, T. Hofstetter, U. Von Gunten, B. Wehrli, Annu. Rev. Environ. Resour., 35, 109-136 (2010)

3. J. Patterson, C. Smith, J. Bellamy, J. Environ. Manage., 128, 441-452 (2013)

4. P. Klimaszyk, P. Rzymski, Water Management and the Environment: Case Studies, 255-278 (2018)

5. F. Sacher, F. Lange, H. Brauch, I. Blankenhorn, J. Chromatogr. A, 938(1-2), 199-210 (2001)

6. D. Kolpin, E. Furlong, M. Meyer, E. Thurman, S. Zaugg, L. Barber, H. Buxton, Environ. Sci. Technol., 36(6), 1202-1211 (2002)
7. IMS Health \& Quintiles IQVIA, Pharmaceutical Market in 2017, (2018)

8. D. Ashton, M. Hilton, K. Thomas, Science of the Total Environment, 333(1-3), 167-184 (2004)

9. C. Thomas, P. Conrad, R. Casler, E. Goodman, Psychiat. Serv., 57(1), 63-69 (2006)

10. K. Kümmerer, Annu. Rev. Environ. Resour., 35, 5775 (2010)

11. S. de García, G. Pinto, P. Encina, R. Mata, Science of the Total Environment, 444, 451-465 (2013)

12. T. Van Boeckel, S. Gandra, A. Ashok, Q. Caudron, B. Grenfell, S. Levin, R. Laxminarayan, Lancet. Infect. Dis., 14(8), 742-750 (2014)

13. B. Kasprzyk-Hordern, A. Dabrowska, N. Vieno, L. Kronberg, J. Nawrocki, Chem. Anal-Warsaw, 53(2), 289, (2008)

14. K. Stein, M. Ramil, G. Fink, M. Sander, T. Ternes, Environ. Sci. Technol., 42(17), 6415-6423 (2008)

15. M. Huerta-Fontela, M. Galceran, F. Ventura, Environ. Sci. Technol., 42(18), 6809-6816 (2008)

16. A. Kot-Wasik, A. Jakimska, M. Śliwka-Kaszyńska, Environ. Monit. Asses., 188(12), 661 (2016)

17. C. Carlsson, A. Johansson, G. Alvan, K. Bergman, T. Kühler, Science of the Total Environ., 364(1-3), 67-87 (2006)

18. H. Yamamoto, Y. Nakamura, S. Moriguchi, Y. Nakamura, Y. Honda, I. Tamura, Y. Hirata, A. Hayashi, J. Sekizawa, Water Res., 43(2), 351-362 (2009)

19. L. Yin, R. Ma, B. Wang, H. Yuan, G. Yu, RSC ADV., 7(14), 8280-8287 (2017)

20. M. Gross-Sorokin, S. Roast, G. Brighty, Environ. Health Perspect., 114(Suppl 1), 147. (2006)

21. K. Kidd, P. Blanchfield, K. Mills, V. Palace, R. Evans, J. Lazorchak, R. Flick, PNAS, 104(21), 8897-8901 (2007)

22. C. Harris, P. Hamilton, T. Runnalls, V. Vinciotti, A. Henshaw, D. Hodgson, T. Coe, S. Jobling, C. Tyler, J. Sumpter, Environ. Health Perspect., 119(3), 306 (2011)

23. K. Fent, Effects of pharmaceuticals on aquatic organisms. Pharmaceuticals in Environment. 175203 (2008)

24. M. Cleuvers, Toxicol. Lett. 142, 185-194 (2003)

25. R. Wilson, P. Reuter, M. Wahl, Mar. Biol., 147(5), 1165-1172 (2005)

26. A. Robson, R. Wilson, C. de Leaniz, Mar. Biol., 151(3), 1195-1204 (2007)

27. A. Robson, G. Thomas, C. de Leaniz, R. Wilson, Aquat. Biol., 6, 191-200

28. A. Marchlewicz, U. Guzik, D. Wojcieszynska, Ochr. Sr., 37(1), 65-70 (2015)

29. A. Szymonik, J. Lach, Inz. i Ochr. Sr., 15(5) 249-263 (2012)

30. T. Brodin, J. Fick, M. Jonsson, J. Klaminder, Science, 339(6121), 814-815 (2013)

31. J. Klaminder, M. Jonsson, J. Fick, A. Sundelin, T. Brodin, Environ. Res. Lett., 9(8), 084003 (2014)

32. M. Bueno, C. Boillot, D. Munaron, H. Fenet, C. Casellas, E. Gomez, Anal. Bioanal. Chem. 406(2), 601-610 (2014)

33. P. Fong, A. Ford, Aquat. Toxicol., 151, 4-13 (2014) 
34. C. Di Poi, K. Costil, V. Bouchart, M. HalmLemeille, Environ. Sci. Pollut. R., 25(7), 6122-6134 (2018)

35. L. Minguez, J. Pedelucq, E. Farcy, C. Ballandonne, H. Budzinski, M. Halm-Lemeille, Environ. Sci. Pollut. Res. 23(6), 4992-5001 (2016)

36. J. Chmist, K.Szoszkiewicz, D. Drożdżyński, Arch Environ Contam Toxicol 77, 432-442 (2019)

37. J. Chmist, K. Szoszkiewicz, Ochr. Sr., 39(2), 39-43. (2017) 